\title{
Estimating Building Airtightness from Data - A Case Study
}

\author{
Christoffer Rasmussen ${ }^{1 *}$, Christian Anker Hviid ${ }^{2}$, Peder Bacher $^{1}$, Davide Cali ${ }^{1}$ and Henrik Madsen ${ }^{1}$ \\ ${ }^{1}$ DTU, Department of Applied Mathematics and Computer Science, 2800 Kgs. Lyngby, Denmark \\ ${ }^{2}$ DTU, Department of Civil Engineering, 2800 Kgs. Lyngby, Denmark
}

\begin{abstract}
The focus on energy conservation in buildings is increasing. Despite that, the yearly building renovation rate is only at around $1 \%$. To increase the renovation rate, new and time-efficient methods used for screening of large building portfolios' energy saving potential are needed. In this paper, a re-engineered take on the classical energy signature method is applied to two renovated apartments in Denmark. The energy signature model relies on time-series measurements of space heat consumption, outdoor temperature, solar irradiation, and wind speed. The estimates obtained from it consist of - among other things - heat loss coefficient and wind-induced heat loss. This paper focuses on the latter. To validate the model estimate, the airtightness has been quantified by blower door-tests in both apartments: the results showed that one apartment is reasonable airtight, while the other suffers from significant air leakages. The energy signature and two other infiltration models, based on blower door test results, were compared. Good agreement between the results obtained from the data-driven energy signature and the blower door test were found. With use of a simple linear relation between the average infiltration and the blower door test result $\left(q_{50}\right)$, from the Danish national building code, the energy signature was found to overestimate the blower door test result $\left(q_{50}\right)$ by $33 \%$ for the leaky apartment and underestimate the same air flow by $18 \%$ for the other apartment. Both estimates are within the standard error of the infiltration model in the Danish national building code.
\end{abstract}

\section{Introduction}

The energy efficiency directive (EED) of the European Union (EU) [1] requires all member states to install individual energy meters (heat meters and electricity meters) on all buildings to the extent that it is technically possible and economically feasible by January 1, 2027.

Furthermore, the building stock accounts for $40 \%$ of the total energy end-use in the EU [2], and the heating energy in households alone accounts for $16 \%$ [3].

With the combination of increasing collections of building energy consumption data and the significant energy use in buildings, it is clear that scalable and datadriven methods for building energy efficiency screenings are more relevant than ever and fundamental to understand where to act first. Moreover, such datadriven methods can play a role in identifying issues in the many buildings that are affected by the energy performance gap [4]-[8].

Often the thermal insulation of buildings is put into focus when dealing energy performance of buildings and especially in the context of data-driven methods for energy performance screening. A significant part of the heat loss through the envelope is, however, not necessarily related to heat transfer such as conduction, convection, and radiation through the constructions, but rather air leakages in the building envelope. This is typically referred to as ex- and infiltration, or simply infiltration.

In a simulation study of 25 American office buildings, it was found that $33 \%$ of the heating loads were related to air infiltration [9]. The same percentage is found for American homes in [10].

In [11] it is further stated that due to increasing insulation levels, the share of energy lost by air infiltration also increases. In some cases, the heating load, which compensate for infiltration, is up to $50 \%$ of the total energy requirement for the building.

Today, the quantification of air infiltration in buildings is typically done by experimental methods such as blower door or tracer gas tests.

Depending on the national building code the requirement of a building's air tightness and how it is documented varies. However, according to the Danish building code all new buildings (or a representative sample) have been required to pass a blower door test since 2006 [12]. Despite a valid blower door test, the result is a point-in-time verification and does not account for continuous degradation for building materials and possible increasing levels of air leakages. With a cost between $270 €$ and $1600 €$ (2020 prices in the Danish market) [13] it is not feasible to redo blower door tests on regular basis - or test all buildings from before 2006 for that matter. This paper proposes a fast, less cumbersome method to determine the level of

\footnotetext{
*Corresponding author: chrras@dtu.dk
} 
building air leakages from heat consumption and weather data.

\subsection{Data-driven thermal building models}

Different kinds of models are widely used in the field of building engineering in order to quantify the energy consumption and the indoor environment. The models can be divided in two categories. Either they rely on detailed information concerning the building in the form of technical drawings, system specifications, comfort requirements etc., or they rely on measurements of e.g. energy consumption, indoor environmental variables, and local weather conditions.

The former category of models deals with what is called forward problems, and the latter category deals with inverse problem. The inverse problem is the opposite of a forward problem and its aim is to identify the causal factors which have produced a given set of observed effects. These models are typical statistical models with a strong connection to the physical understanding of the problem.

Various models used for identification of thermal building properties exist in the literature. Some examples are linear regression models, dynamical autoregressive models, such as ARX and ARMAX models [14]-[16], and stochastic differential equation (SDE) based state space models [14], [17], [18].

A subset of the linear regression models is the energy signature, which typically relates the outdoor temperature to the heat consumption in order to determine a building's heat loss coefficient [19], [20].

Recently, a re-engineered energy signature model was proposed [21]. Along with the heat loss coefficient and other parameters, the new energy signature model provides an estimate of the heat loss related to the effect of wind. In the present article, a detailed analysis of this wind induced heat loss and its relation to the buildings air leakage is investigated. Specifically, the aim of the present case study is to:

1. Describe and apply the energy signature model from [21] in order to estimate the air infiltration based on space heating and weather data, including wind speed.

2. Compare results obtained from the energy signature model to experimental data from blower door test.

3. Compare estimated infiltration with infiltration obtained from the Alberta Infiltration Model (AIM-2) [22].

\subsection{Outline}

This article is structured as follows. In Section 2 (Method) two models, relying on the building leakage coefficient and exponent obtained from a blower door test, are described. The data-driven energy signature model from [21] is briefly outlined and the deduction of the infiltration rate from the model is described. Section
3 (Test cases) briefly outlines the two test cases, and in Section 4 (Results) the infiltration estimates from the experimental- and data-based air infiltration models are presented. In Section 5 (Discussion) the findings are discussed and finally, in Section 6 (Conclusion), the results are summarised and suggestions for further improvement to the energy signature model are discussed.

\section{Method}

The diagram

Figure 1 shows two approaches used in this paper to estimate the infiltration. An experimental approach relying on blower door test results and a data-driven approach using heat meter data and local weather data.

Experimental

Data-driven

Blower door test $\rightarrow \quad$ Infiltration $\leftarrow$ Energy signature

Figure 1. Two approaches used to estimate the infiltration rate in buildings.

\subsection{Infiltration derived from experiments}

A lot of research has been put into the field of translating blower door test results into infiltration rates. Some of the simpler models to estimate the average inuse infiltration rate is typically found in national building codes [23]. However, more elaborated models which include the actual wind and temperature condition, exists as well. One of them is the Alberta Infiltration model (AIM-2) found in [22].

\subsubsection{Average infiltration}

The Danish national building code specifies a simple relation between the infiltration air flow obtained from a $50 \mathrm{~Pa}$ blower door test $\left(q_{50}\right)$ and the average infiltration rate during occupied periods $\left(q_{i}\right)$ [12], [24],

$$
q_{i}=0.06 \cdot q_{50}+0.04 .
$$

The same formula can be found in [25], where it is shown that the relation is found by simple regression on 25 Canadian houses. The standard error of the estimated infiltration rate is $52.4 \%$.

As Equation (1) only provides a single global average for the infiltration, the method will only be used as a reference and for estimating the yearly infiltration rate from $50 \mathrm{~Pa}$ blower door test.

\subsubsection{The Alberta infiltration model (AIM-2)}

Different factors influence the infiltration in buildings. That being the pressure difference across the building envelope, the distribution of openings (including cracks), their shape, size, and flow characteristics [11].

While the infiltration formula in Equation (1) neglects these dependencies, the Alberta Infiltration 
Model (AIM-2) model includes them [22]. In the following, the different components of the AIM-2 model are outlined.

The wind pressure $p_{w}$ is increasing quadratically with the wind speed $W_{s}$ as

$$
p_{w}=\frac{\rho \mathrm{C}_{\mathrm{p}} \mathrm{W}_{\mathrm{s}}^{2}}{2}
$$

where $\rho$ is the air density $\rho$ and $C_{p}$ is the static pressure coefficient [11].

The pressure coefficient can be found from wind tunnel experiments of a downscaled model of the building and its surroundings or measurements on the façade. Naturally, this is not feasible to do under normal circumstances, hence the AIM-2 model uses tabulated shelter coefficients instead of the static pressure coefficient. The wind pressure is therefore determined by

$$
p_{w}=\frac{\rho\left(S_{w} W_{s}^{*}\right)^{2}}{2}
$$

where $S_{w}$ is the shelter coefficient and $W_{s}^{*}$ is the unobstructed wind speed at eaves height. $W_{S}^{*}$ is determined by

$$
W_{s}^{*}=\left(\frac{600}{z_{m}}\right)^{p_{m}}\left(\frac{H}{600}\right)^{p_{s}} W_{s},
$$

where $Z_{m}$ is the hight at which the wind speed measurements are taken, $H$ is the building's eaves height, and $p_{m}$ and $p_{s}$ are the wind speed exponents describing the terrain roughness for the weather station and the site, respectively. The parameters $p_{m}$ and $p_{s}$ take different values depending on whether the wind speed is above or below $3 \mathrm{~m} / \mathrm{s}$.

The stack pressure caused by the buoyant force is changing linearly with the height for fixed indoor and outdoor temperatures. In the heating season, the stack effect results in warm air leaving the building through openings located at high levels in the building and cold air entering the building through openings at low heights. The stack pressure $p_{s}$ is determined by

$$
p_{s}=\rho g H \frac{T_{i}-T_{a}}{T_{i}},
$$

where $g$ is the gravitational acceleration, $H$ is the height of the building, and $T_{i}$ and $T_{a}$ are the indoor and ambient outdoor air temperature, respectively [11], [22].

Theoretically, the wind and stack induced air flows $\left(Q_{w}\right.$ and $\left.Q_{s}\right)$ can be added as

$$
Q=\left(Q_{w}^{1 / n}+Q_{s}^{1 / n}\right)^{n}
$$

where $n$ is the building leakage exponent obtained from a blower door test, and typically lie between 0.5 and 1.0 [11].

In the AIM-2 model, however, the total air flow is reformulated such that it accounts for interactions between the wind and stack flow. Equation (6) is therefore extended in the AIM-2 to

$$
Q=\left(Q_{w}^{1 / n}+Q_{s}^{1 / n}+\mathrm{B} 1\left(Q_{w} Q_{s}\right)^{1 /(2 n)}\right)^{n},
$$

where $\mathrm{B} 1=-0.33$ is the interaction parameter.

The flows in Equation (6) and (7) are specified as

$$
Q_{w}=C f_{w} p_{w}^{n}
$$

and

$$
Q_{s}=C f_{s} p_{s}^{n},
$$

where $C$ is the total building leakage coefficient, which can be determined by a blower door test, and $f_{w}$ and $f_{s}$ are the wind and stack flow factors, which take the leakage locations into account.

The wind factor and the stack flow factor are found empirically in the AIM-2 model. In particular, the wind factor is determined by

$$
f_{w}=0.19(2-n)\left(1-\left(\frac{X+R}{2}\right)^{3 / 2}\right),
$$

and the stack flow factor by

$$
f_{s}=\left(\frac{1+n R}{n+1}\right)\left(\frac{1}{2}-\frac{1}{2}\left(\frac{X^{2}}{2-R}\right)^{5 / 4}\right)^{n+1},
$$

where $R$ and $X$ are the leakage distribution parameters defined as

$$
R=\frac{C_{c}+C_{f}}{C}
$$

and

$$
X=\frac{C_{c}-C_{f}}{C} .
$$

In Equation (12) and (13) $C_{c}$ and $C_{f}$ are the leakage coefficients for the ceiling and the floor, respectively. The sum of $C_{c}, C_{f}$ and a third leakage coefficient for the walls, $C_{w}$, equals the total building leakage coefficient, $C$. Hence, $C_{c}, C_{f}, C_{w}$, and the building leakage coefficient, $C$, share the same unit.

\subsection{Infiltration derived from in-use data}

The energy signature model described in [21] suggests that the heat demand, $\Phi_{h}$, can be estimated as

$$
\begin{gathered}
\Phi_{h}=L S E\left[\left(U A_{O}+W_{s} U A_{w}\right)\left(T_{b_{0}}-T_{a}\right)\right. \\
\left.-g A I_{g}, \Phi_{0}\right]+\varepsilon,
\end{gathered}
$$

where LSE is the smooth maximum function, LogSumExp, described in [21], $\mathrm{UA}_{0}$ is the heat loss coefficient of the building without any contribution from the wind, $W_{s}$ is the wind speed, $\mathrm{UA}_{\mathrm{w}}$ is the heat loss caused by the wind, $\mathrm{T}_{\mathrm{b}_{0}}$ is the base temperature (i.e. the outdoor temperature at which the building is in thermal balance) given the base heating load, $\Phi_{0}$, is zero. $T_{a}$ is the ambient outdoor temperature, gA is the solar transmittance, $I_{g}$ is the global solar irradiation and $\varepsilon$ is the normal distributed error term of the model. 
The model parameter $\mathrm{UA}_{\mathrm{w}}$ expresses the increment in the heat load for each unit of increment of the wind speed. With the given wind speed observations, the infiltration heat loss can be calculated as

$$
\Phi_{i}=\mathrm{UA}_{\mathrm{w}} W_{s},
$$

and the infiltration air flow as

$$
q_{i}=\frac{\Phi_{i}}{c_{p} \rho}
$$

where $c_{p}$ is the specific heat capacity of the air and $\rho$ is the density.

\section{Test cases}

The capabilities of the energy signature to estimate the infiltration air flow will be based on two test apartments located in Aalborg, Denmark. Both apartments were deeply refurbished within the last five years. In Table 1, the key information on the two apartments is listed.

Table 1. Specification of Apartment A and B used as test cases.

\begin{tabular}{lcc}
\hline & Apartment A & Apartment B \\
\hline Heated floor area & $65 \mathrm{~m}^{2}$ & $93 \mathrm{~m}^{2}$ \\
Façade (N/S/E/W) & $25 / 0 / 23 / 9 \mathrm{~m}^{2}$ & $0 / 0 / 21 / 25 \mathrm{~m}^{2}$ \\
Data collection start & Aug. 23, 2019 & Aug. 30, 2019 \\
Data collection end & Jun. 10, 2020 & Jun. 6, 2020 \\
No. of observations & 231 & 88 \\
Leakage coef. $(\mathbf{C})$ & $3.2 \mathrm{1} / \mathrm{s} / \mathrm{Pa}^{\mathrm{n}}$ & $6.1 \mathrm{l} / \mathrm{s} / \mathrm{Pa}^{\mathrm{n}}$ \\
Leakage exp. (n) & 0.797 & 0.891 \\
\hline
\end{tabular}

Both apartments were occupied during the measurement campaign. Furthermore, the occupants of Apartment A have complained about a draught.

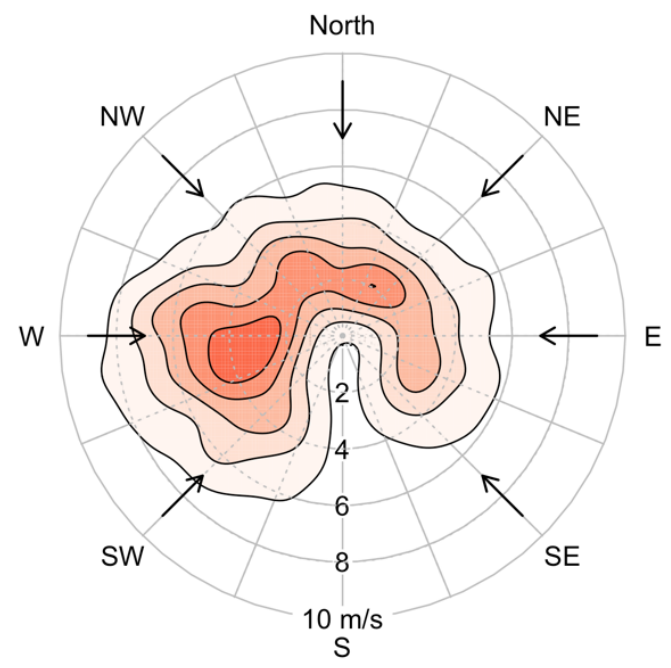

Figure 2. Wind directions and speed $(10 \mathrm{~m})$ at building site obtained from August 2019 to June 2020. Darker colours in the density plot means more frequent observation.
Outdoor temperatures, global solar irradiation, and wind conditions are obtained from the ERA5-land data set from the Copernicus Climate Data Store [26]. In Figure 2 the recorded wind speeds and directions are shown.

The model parameters of the AIM-2 model presented in Section 2.1.2 can be looked up from tables in [22]. However, it is not possible to estimate exact values for the given buildings, hence a reasonable range for each of them is selected and listed in Table 2.

Table 2. AIM-2 model parameter ranges. Parameters are assumed to be uniformly distributed and uncorrelated.

\begin{tabular}{lc}
\hline AIM-2 parameter & Range (uniform dist.) \\
\hline$S_{w}$ & $0.70-0.90$ \\
$C_{c} / C$ & $0.15-0.70(*)$ \\
$C_{f} / C$ & $0.15-0.70(*)$ \\
$C_{w} / C$ & $0.15-0.70(*)$ \\
$p_{m}$ and $p_{s}\left(W_{s}>3 \mathrm{~m} / \mathrm{s}\right)$ & $0.16-0.32$ \\
$p_{m}$ and $p_{s}\left(W_{s} \leq 3 \mathrm{~m} / \mathrm{s}\right)$ & $0.27-0.38(* *)$ \\
\hline \multicolumn{2}{r}{$* *$ Always higher than corresponding values for $W_{s}>3 \mathrm{~m} / \mathrm{s}}$.
\end{tabular}

\section{Results}

With the given set of outdoor and indoor temperature observations, the correlation between them, and the parameters from Table 2, the reasonable limits of the AIM-2 model's infiltration flows can be obtained as a function of the wind speed. This is illustrated in Figure 3 as the un-hatched areas for Apartment A and B (solution space).

The upper and lower limit of the solution space of the AIM-2 model increase non-linearly with the wind speed as seen in Figure 3.

From Equation (5) and (9) it is seen that

$$
Q_{s}=C f_{s}\left[\rho_{o} g H \frac{T_{i}-T_{a}}{T_{i}}\right]^{n},
$$

and in addition, it is found that the correlation

$$
\operatorname{corr}\left(\left(T_{i}-T_{a}\right) / T_{i}, W_{s}\right)<0.057 \approx 0,
$$

for outdoor temperatures, $T_{a}$, lower than $15^{\circ} \mathrm{C}$. Consequently, the stack induced air flow, $Q_{S}$, is uncorrelated with the wind speed, and the relation between the wind speed and the air flow is constant (see Figure 4). Thus, the increasing mean and variance of the AIM-2 solution space found in in Figure 3 are caused by the wind induced pressure alone. 

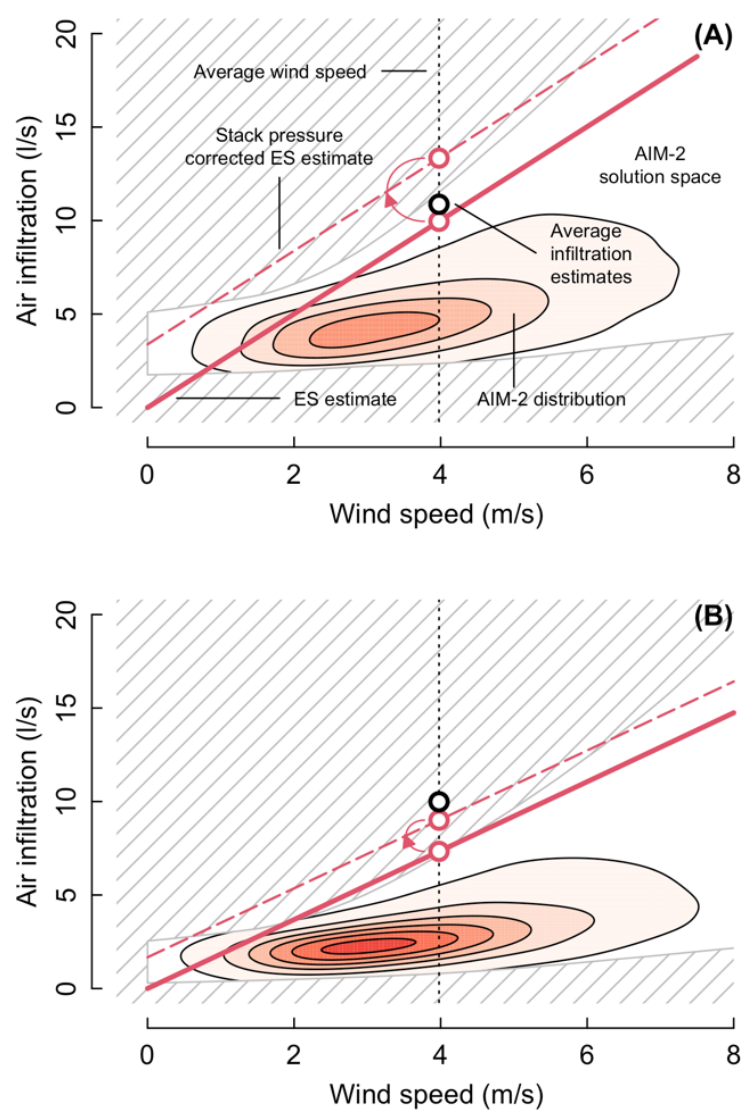

Figure 3. Air infiltration of Apartment A and B estimated with the energy signature model (red solid line), the AIM-2 model (reddish density plot where darker colours correspond to higher densities), and the simple average infiltration consideration (black circle). The dashed red line indicates a corrected energy signature estimate accounting for stack induced air flow, and the two red circles indicates the mean air infiltration obtained by the energy signature model. The AIM-2 solution space and distribution is obtained by simulating 10.000 scenarios given the parameters in Table 2 and the observed temperature and wind conditions.

The distribution of the AIM-2 infiltration flow is obtained given the temperatures, wind speed, and parameters from Table 2. This is illustrated with the red coloured density plot in Figure 3 alongside the estimated infiltration flow obtained from the data-driven energy signature model in Equation (14)-(16) (red line).

With an average wind speed of $4.0 \mathrm{~m} / \mathrm{s}$ for the measurement period the estimated air infiltration with the energy signature model is $10.0 \mathrm{l} / \mathrm{s}$ for Apartment A and $7.3 \mathrm{l} / \mathrm{s}$ for Apartment B. However, the energy signature assumes that the heat loss related to infiltration - and consequently the air flow - is zero in the absence of wind (i.e. wind speed equals $0 \mathrm{~m} / \mathrm{s}$ ). From the AIM-2 model it is clear that an additional mean stack induced air flow of approximately $3.5 \mathrm{l} / \mathrm{s}$ and $1.5 \mathrm{l} / \mathrm{s}$ for Apartment A and B is found in the absence of wind. Furthermore, as the stack induced air flow is constant as described earlier, it is reasonable to believe that the energy signature is underestimating the total infiltration air flow by $3.5 \mathrm{l} / \mathrm{s}$ and $1.5 \mathrm{l} / \mathrm{s}$ for Apartment $\mathrm{A}$ and $\mathrm{B}$, respectively. This is indicated with the curved red arrow and the red dashed straight line.

The last thing illustrated in Figure 3 is the simple average infiltration obtained from the Danish building code and presented in Equation (1). This is illustrated with a black circle. The corresponding average estimate obtained from the energy signature model (with and without the stack pressure correction) is indicated with two red circles.

In Figure 4 the temporal variations of the estimated infiltration air flow obtained from the AIM- 2 model and the data-driven energy signature model are illustrated. For better comparison of the variation the AIM-2 and the energy signature results are shifted by $5 \mathrm{l} / \mathrm{s}$.

As mentioned earlier, the stack induced air flow (grey areas) is roughly constant. However, the temporal variation of the wind induced air flow obtained from the AIM-2 model and the energy signature are close to identical except for a constant of $5 \mathrm{l} / \mathrm{s}$. This supports the energy signature's capabilities of estimating the wind induced air infiltration rate.

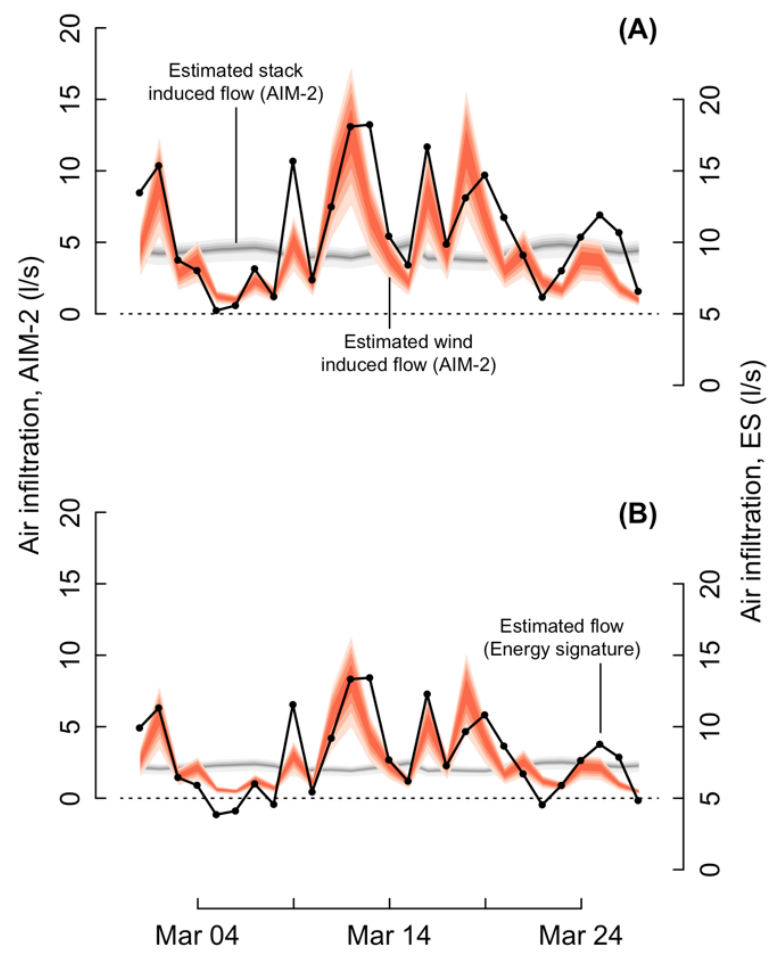

Figure 4. Estimated temporal stack and wind induced infiltration air flows by AIM-2 model (left axis) and air flow estimated by the data-driven energy signature model (right axis). The air flows from the two models are shifted by $5 \mathrm{l} / \mathrm{s}$ (see left and right axes) for better comparison. Notice that the total AIM-2 air flow is not the simple sum of the stack and wind induced flow (see Equation (7)).

\section{Discussion}

From Figure 3 several interesting things are observed. To begin with, it is seen that the distribution of the daily air infiltration flows obtained from the AIM-2 model and the energy signature model are different in three distinct ways. 
First, the estimated infiltration air flows are in general lower for the AIM-2 model than for the energy signature model. The reason for this is that the AIM-2 results are affected by the experimental setup of the blower door test. This implies that all adjustable openings were closed and remaining intentional openings sealed during the blower door test [26]. The AIM-2 model, therefore, indirectly assumed the openings to remain closed and sealed in the in-use periods as well. In contrast to this, the estimated infiltration from the energy signature model is estimated based on in-use data with such openings unsealed resulting in a higher infiltration air flow.

The second thing which distinguish the AIM-2 and the energy signature model is the relation between wind speed and infiltration air flow. The energy signature model in Equation (14) assumes a linear relation between the wind speed and the infiltration, whereas the AIM-2 model has a quadratic relation as seen in Equation (3). As the infiltration obtained from the energy signature is a linear approximation of convex data (see Figure 3), the energy signature model is likely to underestimate the effect of the wind for mid-range wind speeds and otherwise overestimate it.

The third difference is that the energy signature does not describe air infiltration caused by stack pressure directly. As described earlier, the mean stack induced air flow as a function of the wind speed is constant and also proportional with the heat loss through the building fabric due to temperature differences between inside and outside. Consequently, the stack induced heat loss cannot be separated from the heat loss coefficient $\left(U A_{0}\right)$ in the energy signature model. Hence, the infiltration estimate obtained from the energy signature model only reflects the wind induced infiltration.

The occupants of Apartment A have complained about exceptional draught from the kitchen hood. This is clearly backed up by the infiltration estimate given by the energy signature model seen in Figure 3, and the blower door tests.

Using the average infiltration rate obtained from the energy signature and Equation (1) an expected blower door result $\left(q_{50}\right)$ can be obtained. The results are shown in Table 3.

Table 3. Building leakage for Apartments A and B obtained experimentally and by means of data-driven methods.

\begin{tabular}{lcc}
\hline & \multicolumn{2}{c}{ Building leakage $\left(\boldsymbol{q}_{\mathbf{5 0}}\right)$} \\
\cline { 2 - 3 } & Apartment A & Apartment B \\
\hline Energy signature $(*)$ & $2.8 \mathrm{l} / \mathrm{s} / \mathrm{m}^{2}$ & $0.9 \mathrm{l} / \mathrm{s} / \mathrm{m}^{2}$ \\
Blower door test & $2.1 \mathrm{l} / \mathrm{s} / \mathrm{m}^{2}$ & $1.1 \mathrm{l} / \mathrm{s} / \mathrm{m}^{2}$ \\
Deviation (ES/BDT) & $+33 \%$ & $-18 \%$ \\
\hline
\end{tabular}

* Average infiltration after stack pressure correction.

The energy signature has overestimated the building leakages at $50 \mathrm{~Pa}$ by $0.7 \mathrm{l} / \mathrm{s} / \mathrm{m}^{2}(33 \%)$ compared to the blower door test result. One reason for the discrepancy might be related to the linear formulation of the infiltration as a function of the wind speed, which is in contrast to the actual non-linear relation between wind speed and the infiltration flow.

The building leakage at $50 \mathrm{~Pa}$ obtained from the energy signature for the more airtight building (Apartment B) only deviates by $0.2 \mathrm{l} / \mathrm{s} / \mathrm{m}^{2}(18 \%)$.

\section{Conclusion}

The study has demonstrated the differences between three models used for estimating the building leakage on two deeply refurbished apartments in Aalborg, Denmark. Both apartments have been tested by means of a blower door test, and one apartment was found to be very leaky.

Two models relying on the building leakage information obtained from a blower door test were found in the literature. One of them being a simple linear relation between the air flow under a $50 \mathrm{~Pa}$ blower door test and the average infiltration rate. The other model (the AIM-2 model) being more advanced in the sense that it accounts for stack and wind pressure, leakage distribution etc., but still relying on blower door test results.

The third model was the data-driven energy signature model for estimating the building heat demand purely based on heat consumption and weather data [21]. Among other model parameters, one of them accounts for the heat loss related to the wind speed. This parameter was used to estimate the infiltration rate.

The energy signature model and the simple regression model for estimating the average infiltration rate showed good agreement. The AIM- 2 model on the other hand, suffered from the fact that it relied on the blower door experimental setup-e.g. closed kitchen hoods and sealed intentional openings. Consequently, the AIM-2 model seems not to resemble the in-use infiltration rate, and generally estimates lower infiltration rates than the two other models.

Despite the low infiltration rate obtained from the AIM-2 model, it was found that the energy signature might benefit from modelling the infiltration in a nonlinear way instead of linear.

Additionally, the energy signature model is not able to distinguish between heat loss related to stack pressure and other heat losses caused by the temperature difference between inside and outside. The estimated infiltration heat loss from the energy signature model is therefore only related to wind speed qua the model formulation.

The data-driven energy signature method has shown promising results in regard to estimating air leakages in buildings. Based on the energy signature model from [21], the blower door test result was predicted. The difference between the blower door test result $\left(\mathrm{q}_{50}\right)$ and the prediction was as low as $0.2 \mathrm{l} / \mathrm{s} / \mathrm{m}^{2}$ or $18 \%$ for the apartment with low air leakage. For the leaky apartment a difference of $0.7 \mathrm{1} / \mathrm{s} / \mathrm{m}^{2}$ or $33 \%$ with $50 \mathrm{~Pa}$ pressure difference was found. 
With the limited amount of data from the apartments the estimates are appraised rather accurate. In addition, both estimates are within the standard error of the simple infiltration model (52.4\%) as described in Section 2.1.1. Despite the promising results, future studies on various building geometries and sizes, as well as richer data sets are suggested in order to get a better understanding of the model accuracy. Likewise, a more elaborate analysis on the method's sensibility to its input variables might be beneficial to strengthen the understanding of datadriven air leakage estimation.

Acknowledgments: This work was supported by the project SmartTune founded by The Research Council of Norway (296345); Centre for IT-Intelligent Energy Systems in Cities (CITIES) founded by the Danish Innovation Fund (DSF130500027B-CITIES); and Renovating Buildings Sustainably (REBUS) (5151-00002B) which provided the data.

\section{References}

[1] "Directive 2012/27/EU of the European Parliament and of the Council of 25 October 2012 on energy efficiency (EED)," European Union Law. Oct-2012.

[2] European Parliament and European Council, "Directive 2010/31/EU of the European Parliament and of the Council of 19 May 2010 on the energy performance of buildings," Off. J. Eur. Union, vol. 2010, no. L 153, pp. 13-35, 2010.

[3] "Consumption of Energy." Eurostat, 2016.

[4] D. Calì, T. Osterhage, and D. Müller, "Rebound effect related to retrofit solutions for residential housing : monitoring data from a field test," Proc. SB11 Helsinki World Sustain. Build. Conf., pp. 104-113, 2011.

[5] D. Calì, T. Osterhage, R. Streblow, and D. Müller, "Energy performance gap in refurbished German dwellings: Lessonlearned from a field test," Energy Build., no. 127, pp. 1-13, 2016.

[6] A. L. Pisello, C. Piselli, and F. Cotana, "Influence of human behavior on cool roof effect for summer cooling," Build. Environ., no. 88 , pp. 116-128, 2015.

[7] R. Haas and P. Biermayr, "The rebound effect for space heating Empirical evidence from Austria," Energy Policy, no. 6-7, pp. 403-410, 2000.

[8] L. Tronchin and K. Fabbri, "Energy performance building evaluation in Mediterranean countries: Comparison between software simulations and operating rating simulation," Energy Build., vol. 40, no. 7, pp. 1176-1187, 2008.

[9] S. T. Emmerich, A. K. Persily, and T. P. McDowell, "Impact of commercial building infiltration on heating and cooling loads in US office buildings," 26th AIVC Conf. "Ventilation Relat. to energy Perform. Build., no. 1998, 2005.
[10] J. Straube, "Air Leaks - How They Waste Energy and Rot Houses," Fine Home Building, The Taunton Press, no. October/November, pp. 45-49, 2012.

[11] H. B. Awbi, Ventilation of buildings. Taylor \& Francis, 2003.

[12] Trafik- Bygge- og Boligstyrelsen, "The Danish National Building Code, BR18,” 2021.

[Online]. Available: https://bygningsreglementet.dk/. [Accessed: 13-Jan-2021].

[13] S. Frederiksen and G. Clasen, "En blower door-test kan tjekke, om dit nye hus er utæt," Videncentret Bolius, 2020. [Online]. Available: https://www.bolius.dk/brug-en-blower-doortest-til-at-tjekke-om-dit-nye-hus-er-utaet19673. [Accessed: 13-Jan-2021].

[14] C. Rasmussen, "Data-driven Methods for Reliable Energy Performance Characterisation of Occupied Buildings," The Technical University of Denmark, 2020.

[15] M. J. Jiménez, H. Madsen, and K. K. Andersen, "Identification of the main thermal characteristics of building components using MATLAB," Build. Environ., vol. 43, no. 2, pp. 170-180, 2008.

[16] J. P. Real et al., "Characterisation of thermal energy dynamics of residential buildings with scarce data," Energy Build., vol. 230, p. 110530 .

[17] C. Rasmussen, L. Frölke, P. Bacher, H. Madsen, and C. Rode, "Semi-parametric modelling of sun position dependent solar gain using B-splines in grey-box models," Sol. Energy, vol. 195, pp. 249-258, 2020.

[18] P. Bacher and H. Madsen, "Identifying suitable models for the heat dynamics of buildings," Energy Build., vol. 43, no. 7, pp. 1511-1522, 2011.

[19] M. F. Fels and others, "PRISM: An introduction," Energy Build., vol. 9, no. 1-2, pp. 5-18, 1986.

[20] S. Hammarsten, "A critical appraisal of energy-signature models," Appl. Energy, vol. 26, no. 2, pp. 97-110, 1987.

[21] C. Rasmussen, P. Bacher, D. Calì, H. A. Nielsen, and H. Madsen, "Method for scalable and automatised thermal building performance documentation and screening," Energies, vol. 13, no. 15, pp. 1-23, 2020.

[22] I. S. Walker and D. J. Wilson, "The Alberta Air Infiltration Model,” Alberta, 1990.

[23] D. Van Orshoven and A. Tilmans, "Methods in the national EPB-calculation procedures to determine the ventilation heat transfer coefficient," no. March, 2010.

[24] S. Aggerholm and K. Grau, "Bygningers energibehov-SBi-anvisning 213," Build. Res. Institute, Aalborg Univ. Hørsholm, Denmark, 2008. 
[25] H. R. Trechsel and P. L. Lagus, Measured air leakage of buildings: a symposium, vol. 904. ASTM International, 1986.
[26] "EN 13829: Thermal performance of buildings - Determination of air permeability of buildings - Fan pressurization method." Danish Standard, 2000. 